\title{
Implementing a
}

Nursing

Internship

Program

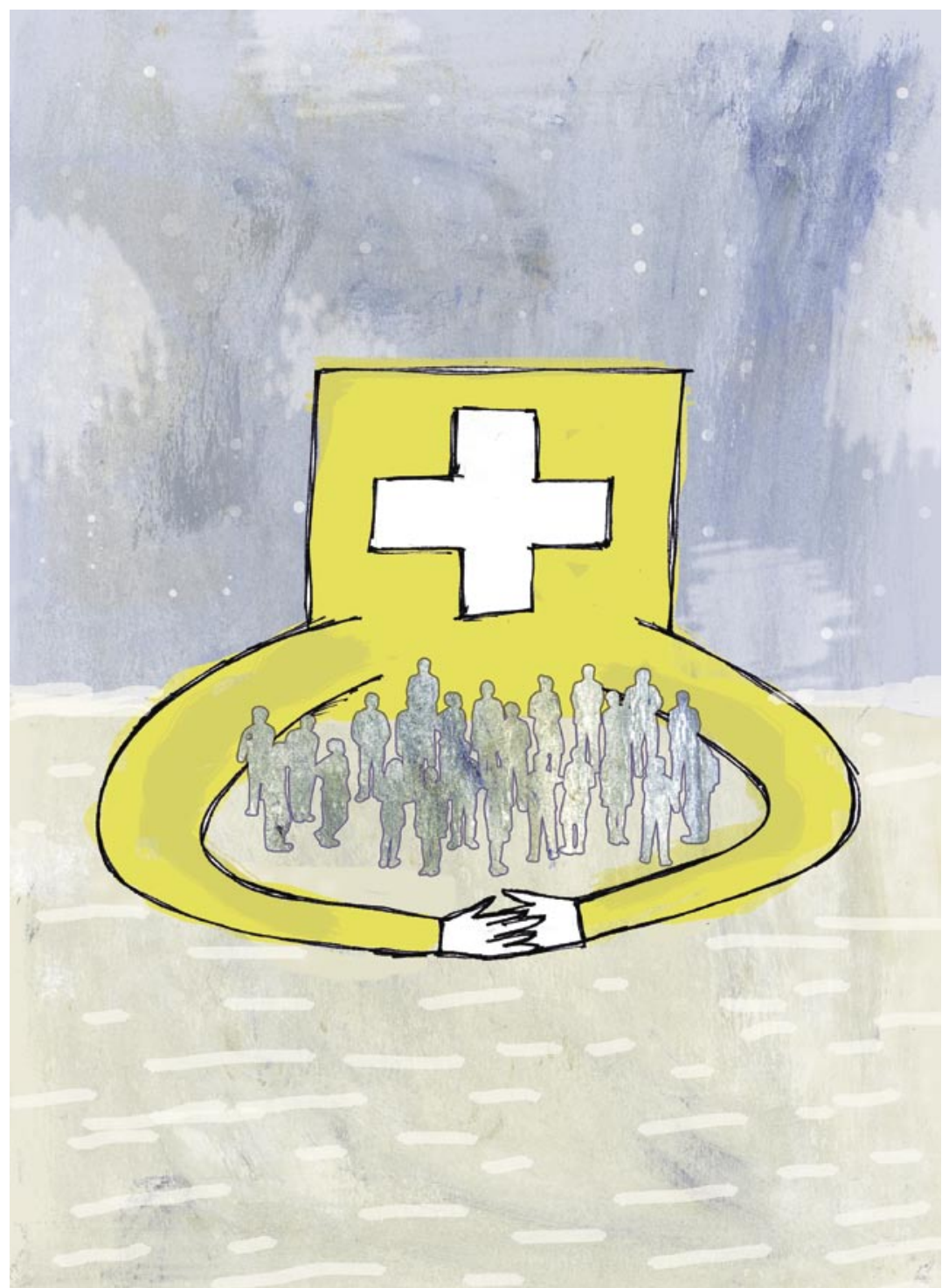

Cheryl Anne Smith

\begin{abstract}
The Ottawa Hospital developed an evidence-based nursing internship program to meet the challenges of new graduates. The literature suggests many challenges that they face during their transition from student to new graduate, with a turnover estimated as high as $60 \%$. The program provides support to new graduates by offering opportunities for growth and autonomy, leading to active participation as team members. Evaluation criteria include satisfaction for interns, preceptors, clinical mangers and educators based on the program objectives, and new graduate turnover. We were able to decrease new graduate turnover from $23 \%$ at two years to $10 \%$, with $\$ 360,000$ in savings from the reduced turnover.
\end{abstract}

A s one of the largest academic health sciences centres in Canada, the Ottawa Hospital was concerned about the impact of the upcoming nursing shortage, estimated to be 78,000 in Canada by 2011, especially in light of the expansion that it was undergoing (Ryten 2002). We recognized that new graduates would be the dominant pool of new hires and developed an internal recruitment strategy that was based on Benner's transition from advanced beginner to competent, with supported time in a medicine or surgery unit followed by the completion of a specialty program to fill the vacancies we would have in critical care and the operating room (Benner 1984). While we did not have the funds to implement the strategy fully, we utilized the Ontario Ministry of Health and Long-Term Care Nursing Enhancement Funds to develop our Nursing Internship program. 
The transition from student to new graduate is a "reality shock."

\section{Program Development}

A literature review was undertaken to identify the challenges that new graduates face and to guide the development of program goals. Kramer (1985) stated that the transition from student to new graduate is a "reality shock." The transition process is a rite of passage with three phases: separation, transition and integration (Winter-Collins and McDaniel 2000). It is also identified that new graduates' sense of belonging is linked to their successful transition into their professional role. New graduates were found to demonstrate stress regarding competence, confidence, making errors and adjusting to new workplace environments and to complain of lack of support and problems with organization, completion of tasks and quality of work (Guhde 2005; Oremann and Garvin 2002). New graduates who complete a nursing internship program have more professional self-confidence and job satisfaction and are less stressed because they are in a supportive environment (Casey et al. 2004; Owens et al. 2001). It has been estimated that it takes new graduates at least one year to master a job with successful organization socialization (Tradewell 1996); they also do not feel skilled, comfortable or confident for as long as one year after hire (Casey et al. 2004). New graduate turnover during the first year is estimated at between 35 and $60 \%$, with $40 \%$ of new graduates perceiving a lack of opportunities for future career development within the organization (Casey et al. 2004; Godinez et al. 1999). New graduates want reassurance, specific and precise guidelines and daily feedback on their clinical skill development (Modic in Guhde 2003). Connelly and Hoffart (1998) found that new graduates need to feel connected to people in the organization or they may not stay long enough to fit in. Novice nurses today still feel the most frustrated by the lack of care and concern they are shown by staff (Meissner 1999).

\section{The Nursing Internship Program}

Our Nursing Internship program is an "earn while you learn" program designed to facilitate the role transition from novice/ novice beginner to competent (Benner 1984). Nursing internships are offered in medicine and surgery, which are the typical throughput units for the specialty programs, and in mental health, where we have a potential retirement rate of $30 \%$ over the next few years. The program provides support to new graduates by offering opportunities for professional growth and autonomy leading to active participation as members of the clinical team. Benefits for the new graduate include increased confidence in knowledge and assessment skills, improved clinical skills and improved decision-making, prioritizing and problem solving skills. The program is a 12-week fully preceptored program that includes orientation for both the preceptor and the intern, includes education days off the unit and is open to new graduates with less than two years' experience. The two-year point is identified as being significant. It is often when new graduates start to assume a leadership role as fully functional team members (Casey et al. 2004).

The goals of program are to promote strategies for new graduate recruitment and retention, to provide an opportunity to consolidate clinical nursing knowledge in new areas of practice and to provide an opportunity to demonstrate understanding and competence in technical skills and procedures related to the specialty in which they are practising. The program also allows for the application of sound clinical judgment and critical thinking throughout the nursing process in the management of patient skills. The development of time-management and delegation skills is another important goal. The interns and the preceptors are supported by a nursing enhancement coordinator, whose job is to coordinate, implement, evaluate and report on the program.

\section{The Preceptors}

Preceptors are selected based on the RN Scope of Practice Assessment Tool; this was developed based on Benner's model (1984). The purpose of the tool is for nurses to self-evaluate their ability to work within the full scope of practice. The tool is based on the Ottawa Hospital's Nursing Professional Practice Model definition and the College of Nurses of Ontario's profile of professional expectations for registered nurses and registered practical nurses. Almada et al. (2004) report that the successful progress from novice to advanced novice nurse is accomplished through a one-to-one relationship, with continuous guidance. The preceptors provide continuous feedback, focusing on the positive steps interns take toward their individual learning goals. The preceptor role begins as a teacher and gradually evolves to a resource person over the 12-week period. Preceptors must be caring, flexible and open, have a positive attitude, be confidence builders and be clinically confident (Guhde 2005). Preceptors are clinical experts in their area and attend a half-day workshop on the role of the preceptor that was developed to address the differences between precepting a student and a novice nurse.

\section{The Interns}

Novice nurses apply and are interviewed for the positions. If nurses have less than one year's experience, they are expected to complete the internship in their unit. If they have between one and two years' experience, they complete the internship in another unit. They all attend a half-day orientation where they write their learning objectives for the program. These objectives are reviewed with the preceptor and the nursing educator. One of their objectives is to become familiar with the nursing and 
healthcare resources that are available to support patient care at the Ottawa Hospital. Workshops and educational sessions are planned during the 12-week period to increase their awareness of the supports available and the organization as a whole.

\section{Evaluation}

Qualitative and quantitative data are collected. The interns complete a post-internship survey. Results have been consistent with the literature. Interns have reported increased job satisfaction, increased confidence, reduced stress, an increased sense of belonging and increased knowledge, critical thinking, decisionmaking, time-management and organizational skills. They also have reported learning many new psychomotor skills and having had the time to become proficient. Finally, interns have noted an increased self-esteem, that they have a better understanding of their role as a professional and that they are more marketable.

The clinical managers and educators have reported high satisfaction with the program and the growth that interns demonstrate during the program.

\section{Interns have noted an increased self-esteem} and that they have a better understanding of their role as a professional.

Both the preceptors and the interns are also asked to complete a post-program survey rating how well the program meets its goals. Overall, $94.1 \%$ of respondents have been very satisfied with the program and would recommend it to others. The questionnaire uses a Likert scale, with 0 indicating not applicable and 4 indicating outstanding. Overall, they rated the program at 3.31 in meeting its goals. The results are presented in Table 1.

New graduate turnover is identified as a major issue in the literature, with reports of turnover being as high as $60 \%$ during the first year (Casey et al. 2004; Godinez et al. 1999). Our two-year new graduate turnover rate was $23 \%$. However, for the 96 graduates of the Nursing Internship program, we had a $10 \%$ turnover rate at two years and a $6 \%$ rate at one year, which is well below the suggested turnover rates of new graduates. Low turnover is defined as being between 4 and 12\% (VHA 2002). Our normal turnover of registered nurses is just over $6 \%$, so we have decreased our turnover for the nursing internship graduates significantly.

Sixteen of the 96 participants, or $16.6 \%$, have moved into the specialty areas such as the Intensive Care Unit, Operating Room and Emergency Department, while $90 \%$ of the nurses who completed their internship in mental health are still working there.

\section{Challenges}

We faced several challenges when we started the program. The first was communication across our five campuses with 11,000 employees and 4,000 nurses. The program started in September, and it turned out that the summer was not the ideal time to get the message out. There was confusion about the program: it is not an extended orientation program for nurses who are struggling; it is designed to meet the needs of the novice/advanced novice nurse looking to move quickly into the specialty areas where our needs will be the greatest. Communicating the role of interns and preceptors to the rest of the unit staff was initially an issue, which we have subsequently resolved. We also had some problems ensuring that the interns would be supernumerary for the complete 12 weeks. This was addressed by changing the timing of the program. Originally, it was to be offered equally throughout the fiscal year. We changed this to have $50 \%$ of
Table 1. Responses in the post-program survey

\begin{tabular}{|c|c|c|c|}
\hline & Preceptors & Interns & Mean \\
\hline \multicolumn{4}{|l|}{ Does the Nurse Internship Program: } \\
\hline - promote recruitment and retention of novice nurses? & 3.5 & 3.3 & 3.42 \\
\hline $\begin{array}{l}\text { - provide an opportunity to consolidate nursing knowledge in a new area of } \\
\text { practice? }\end{array}$ & 3.5 & 3.7 & 3.58 \\
\hline $\begin{array}{l}\text { - provide an opportunity to demonstrate understanding and competence in } \\
\text { technical skills and procedures? }\end{array}$ & 3.6 & 3.1 & 3.42 \\
\hline $\begin{array}{l}\text { - provide an opportunity to apply clinical judgment and critical thinking in the } \\
\text { management of patient care? }\end{array}$ & 3.25 & 3.43 & 3.32 \\
\hline - provide the opportunity to develop time-management and delegation skills? & 3.4 & 3.7 & 3.53 \\
\hline - provide an orientation to the program of choice? & 3.4 & 3.3 & 3.37 \\
\hline - provide adequate support and resources to ensure objectives met? & 3.1 & 3.7 & 3.32 \\
\hline - meet the expectations as outlined in the program? & 3.4 & 3.3 & 3.37 \\
\hline Were the program objectives clearly communicated to the unit staff? & 2.5 & 2.42 & 2.47 \\
\hline
\end{tabular}


the positions starting during the first quarter, with $30 \%$ in September and the final $20 \%$ in January. While we originally envisioned not having interns in the summer or December, we found that many of the clinical managers liked having interns over the summer months to ensure that new graduates had the opportunity to participate in this initiative.

\section{Benefits}

The most significant benefit is the decrease in turnover for this group. The cost of turnover of registered nurses has been estimated at $\$ 25,000$ to over $\$ 60,000$ per nurse who leaves a post in the United States (Bland-Jones 2004; Casey et al. 2004). If we use a conservative estimate of $\$ 30,000$ Canadian, we have saved over $\$ 360,000$ in turnover costs. The interns' progression was noted not just by their clinical manager but also by the preceptors, who took pride in the role they had played. As the program is now finishing its third year, we have developed a cadre of preceptors who are aware of the needs and benefits of supporting new graduates on their units. The interns are not only more connected to the organization, they know the opportunities that exist at the Ottawa Hospital. Patient outcomes have been positively linked to experienced nurses.

\section{If we use a conservative estimate of $\$ 30,000$ Canadian, we have saved over $\$ 360,000$ in turnover costs.}

\section{Conclusion}

While the development and implementation of the Nursing Internship program based on the needs of novice nurses was challenging at times, it has produced many rewards. We did not expect to see such a sudden decrease in our new graduate turnover. The literature suggests that by decreasing the number of new graduates leaving our organization, we are decreasing the number leaving the profession - and therefore contributing to our nursing population (Ulman 2002). The graduates of the program are more confident in their role as nurses and add to the increasing number of specialty trained nurses that we will need to meet the growing needs of our community. $\mathbf{H Q}$

\section{References}

Almada, P., K. Carafoli, J.B. Flatterly, D.A. French and M. McNamara. 2004. "Improving the Retention Rate of Newly Graduated Nurses." Journal for Nurses in Staff Development 20(6): 268-73.

Bartz, K. 1999. "The Orientation Experiences of Urgent Care Nurses: Sources for Learning." Journal for Nurses in Staff Development 15(5): 210-6.

Benner, P. 1984. Novice to Expert: Excellence and Power in Clinical Nursing Practice. Menlo Park, CA: Addison-Wesley.
Bland-Jones, C. 2004. "The Costs of Nurse Turnover". JONA 34(12): $552-70$.

Cantrell, M.A., A.M. Browne and P. Lupinacci. 2005. "The Impact of a Nurses Externship Program on the Transition Process from Graduate to Registered Nurse." Journal for Nurses in Staff Development 21(5): 187-95.

Casey, K., R. Fink, M. Krugman and J. Propst. 2004. "The Graduate Nurse Experience." JONA 34(6): 303-11.

Connelly, L. and N. Hoffart. 1998. "Staff Turnover among Hospital Nurses.” Journal of Nursing Staff Development 14(1): 31-9.

Godinez, G., J. Schweiger, J. Gruver and P. Ryan. 1999. "Role Transition from Graduate to Staff Nurses: A Qualitative Analysis." Journal for Nurses in Staff Development 15(3): 97-110b.

Guhde, J. 2005. "When Orientation Ends ... Supporting the New Nurse Who Is Struggling to Succeed." Journal for Nurses in Staff Development 21(4): 145-9.

Kramer, M. 1985. Reality Shock: Why Nurses Leave Nursing. St. Louis: CV Mosby.

Meissner, J. 1999. "Nurses, Are We Still Eating Our Young?” Nursing 29(2): 42-4.

Oremann, M. and M.F. Garvin. 2002. "Stress and Challenges for New Graduates in Hospitals." Nurse Education Today 22: 220-3.

Owens, D.L., M.A. Turjanica, M.W. Scanion, A.E. Sandhusen, M. Williamson, C. Hebert and L. Facteau. 2001. "New Graduate RN Internship Program: A Collaborative Approach for System Wide Integration." Journal for Nurses in Staff Development 17(3): 144-50.

Ryten, E. 2002. Planning for the Future. Nursing Human Resources Projection. Ottawa, ON: Canadian Nurses Association.

Tradewell, G. 1996. "Rites of Passage: Adaptation of Nursing Graduates to a Hospital Setting." Journal of Nursing Staff Development 12(4): 183-9.

Ulman, M. 2002. "More Nurses Quitting Careers Early: A National Survey of Recent Graduates Said More Men and Women Finding Other Jobs, Aggravating a Shortage." Maine Nurse 4(4): 20.

VHA. 2002. The Business Case for Work Force Stability. Irving, TX: Author. Retrieved September 2004. <http://www.vha.com>.

Winter-Collins, A. and A.M. McDaniel. 2000. "Sense of Belonging and New Graduate Job Satisfaction." Journal for Nurses in Staff Development 16(3): 103-11.

\section{About the Author \\ Cheryl Anne Smith, RN, MScN, is the corporate nursing} recruitment, retention and recognition coordinator at the Ottawa Hospital, in Ottawa, Ontario. She made a career shift in 2000 to work in this position. Her primary responsibilities are the development, coordination, implementation and evaluation of strategic nursing recruitment activities, monitoring of retention patterns and making recommendations. You can reach Ms. Smith by phone at 613-761-4466, by fax at 613-761-4728 or by e-mail at casmith@ottawahospital.on.ca. 